\section{EFFECTIVE MONITORING OF CANAL IRRIGATION WITH MINIMUM OR}

\section{NO FLOW MEASUREMENT}

Cost-effective irrigation system monitoring

B. A. LANKFORD

School of Development Studies, University of East Anglia, Norwich, UK

Abstract

The irrigation literature generally supports the idea that flow measurement is an important precursor to improved monitoring and management of surface irrigation schemes. However, the construction, maintenance and operation of flow measurement structures, coupled with the collection and analysis of data from them, create logistical problems which erode their effective use. In acknowledging this, but still aiming to raise the performance of irrigation, it becomes necessary to think of other ways that monitoring can be conducted while maintaining the value of the information collected In this paper, three avenues are explored, based on; key-location flow measurement; passive flow measurement and no flow measurement. In the discussion under no flow measurement, applicable to rotational irrigation, the concept of irrigation progress per day (ha/day) is introduced. In addition, a brief discussion on the management of monitoring covers linkages with water management, use of computers, devolving responsibility and phased planning of interventions.

Keywords: Canal irrigation, flow measurement, irrigation management, monitoring, performance.

\section{Introduction}

Flow measurement on surface irrigation schemes is often stated to be an important precursor to monitoring and management, summarised in the saying "to measure is to manage." However, numerous problematic factors are involved, resulting in few successful monitoring programmes. Within this large subject-area, this paper discusses a few ways in which managers may introduce and sustain informative, costeffective monitoring of irrigation management and performance.

'Lankford, B. A. 1998. Effective monitoring of canal irrigation with minimum or no flow measurement, in Water and the Environment: Innovative issues in irrigation and drainage, (eds. L. S. Pereira and J.W. in Water and the Environment: Innovative
Gowing), E \& FN Spon, London, 265-273.
The notion that flow measurement is an important part of monitoring of irrigation is widespread: "the existence and location of management tools such as flow measurement and water control structures can influence the managerial decision making process." [1]. "Usually water measurements should be planned at all points where it can be reasonably established that information on the flow rate will affect the management decisions." [2]. A survey among specialists on irrigation performance placed measuring devices within the top five along with performance data and performance criteria [3]. Measuring flows is also termed 'control for supervision' [4]. However, the commonplace situation on irrigation schemes is that flow measurement is not taking place, usually because of a combination of factors such as the difficulty of measuring varying flows; broken structures; difficult-to-operate structures; low staffing and training levels; weakly developed data collection procedures; a lack of motivation of staff and a lack of will on behalf of the managers. Nevertheless, irrigation schemes can and do manage without flow measurement.

\section{An analysis of monitoring}

Perhaps there is a need for effective monitoring rather than 'perfect' monitoring. The question is what is effective monitoring, what factors are involved, and how flexible, scheme-specific and appropriate are they for different levels of the scheme or organisation? Table 1 is an analysis of seven possible factors involved in irrigation monitoring. The left hand column gives the factor and sub-types, the middle column gives the definition and role of the factors, while the right column suggests the level of the irrigation scheme or organisation where the factor would be most appropriate.

Some important points arise from this analysis. Effective monitoring is about utilising each factor in the most cost-effective manner to arrive at available, up-to-date, relevant information. Effectiveness is also about building monitoring in stages; initially on simple questions (e.g. how many irrigations were achieved this season?) to create an interest in irrigation management. Then, monitoring of irrigation management (against management performance targets) can be introduced, and then monitoring of performance indicators (i.e. efficiency and equity) can be considered.

Secondly, flow measurement has a place in monitoring, but need not dominate the debate. The relative omission of flow measurement structures has been discussed by several authors, not least in respect of effective water pricing systems [5]. Further discussion on flow measurement is found in section 3 of this paper.

Thirdly, codification and up-to-date measurement of areas, which are often ignored, are precursors to well-planned (computerised), monitoring. Codification needs to recognise returns to water as well as other reasons for naming fields. Ideally, codes should be attached to the canals, fields and outlets with the lowest unit of flow. The author has visited a scheme where a single code in the record books was in fact four separate "fields" supplied by two separate tertiary canals and outlets. The managers said they found it difficult to determine how long each field took to irrigate. In addition, codes should reflect the connection of fields via the rotation of flows.

The fourth point is that the six factors are interrelated and without each addressed in some way, monitoring may be ineffective or collapse totally. 
Table 1. Analysis of factors involved in monitoring of surface irrigation schemes

\begin{tabular}{|c|c|c|}
\hline $\begin{array}{l}\text { Main factor and } \\
\text { sub-types }\end{array}$ & Definition and role & $\begin{array}{l}\text { Probable best location } \\
\text { for cost-effectiveness }\end{array}$ \\
\hline Codification & $\begin{array}{l}\text { Naming and numbering of infrastructure and place. } \\
\text { For assigning information to areas and locations. }\end{array}$ & $\begin{array}{l}\text { Tertiaries, fields and } \\
\text { farms. }\end{array}$ \\
\hline $\begin{array}{l}\text { Area } \\
\text { measurement }\end{array}$ & $\begin{array}{l}\text { Determining areas irrigated. For use in flow-area- } \\
\text { time calculations }\end{array}$ & $\begin{array}{l}\text { Fields and farms. } \\
\end{array}$ \\
\hline $\begin{array}{l}\text { No. of irrigations } \\
\text { measurement }\end{array}$ & $\begin{array}{l}\text { Determining progress rates of irrigation. See section } \\
3.4 \text { of this paper }\end{array}$ & Fields and farms. \\
\hline $\begin{array}{l}\text { Time } \\
\text { measurement }\end{array}$ & $\begin{array}{l}\text { Measuring start and stop times of irrigation. For } \\
\text { calculating durations and volumes applied }\end{array}$ & Fields and farms. \\
\hline $\begin{array}{l}\text { Flow and/or level } \\
\text { measurement } \\
\text { - Automatic } \\
\text { - Passive manual } \\
\text { - Active manual }\end{array}$ & $\begin{array}{l}\text { Measuring flows and/or levels. For determining } \\
\text { volumes applied and diagnosing problems. } \\
\text { - No or few people involved (e.g. telemetry) } \\
\text { - Flow often set by structure and is known } \\
\text { - Flow is variable and has to be recorded }\end{array}$ & $\begin{array}{l}\text { (Passive and automatic } \\
\text { can work at tertiary } \\
\text { levels). } \\
\text { Active and automatic } \\
\text { measurement at main } \\
\text { and secondary canals. }\end{array}$ \\
\hline $\begin{array}{l}\text { Organisational } \\
\text { procedures } \\
\text { - Informal } \\
\text { - Formal } \\
\text { - Information } \\
\text { - Personnel } \\
\text { - Pathway } \\
\text { - Frequency }\end{array}$ & $\begin{array}{l}\text { Methods of monitoring. For allocating water and } \\
\text { selecting method of monitoring. } \\
\text { - Implicit monitoring against unwritten rules } \\
\text { - Explicit procedures and rules for monitoring } \\
\text { - What is collected (flow, time, place) } \\
\text { - Who collects (farmers, gatekeepers, supervisors) } \\
\text { - How collected (from what/whom to what/whom) } \\
\text { - When collected (daily, weekly, missing data) }\end{array}$ & $\begin{array}{l}\text { Complex } \\
\text { organisational levels } \\
\text { involved; farmers, } \\
\text { gatekeepers, junior and } \\
\text { senior irrigation staff. } \\
\text { 'Flow' of data is } \\
\text { usually from many } \\
\text { junior staff to fewer } \\
\text { senior staff. }\end{array}$ \\
\hline $\begin{array}{l}\text { Evaluation and } \\
\text { relevancy }\end{array}$ & $\begin{array}{l}\text { Use of monitoring information. For demonstrating } \\
\text { benefits and relevancy of monitoring in management. }\end{array}$ & All levels are involved. \\
\hline $\begin{array}{l}\text { - Method } \\
\text { - By/to whom } \\
\text { - To what stage } \\
\text { and format }\end{array}$ & $\begin{array}{l}\text { - Manual or computer } \\
\text { - Who examines results, then to whom are they sent? } \\
\text { - How analysed and what is final form (e.g. irrigation } \\
\text { management measures or performance indicators) }\end{array}$ & $\begin{array}{l}\text { Also depends on stages } \\
\text { of building of } \\
\text { monitoring }\end{array}$ \\
\hline $\begin{array}{l}\text { - Targets } \\
\text { - Irrigation }\end{array}$ & $\begin{array}{l}\text { - What/how are targets set and who sets them } \\
\text { - Can the results be used to identify zones or } \\
\text { operational procedures resulting in poor irrigation? }\end{array}$ & $\begin{array}{l}\text { Traditionally, evaluated } \\
\text { results moves from } \\
\text { senior staff back to }\end{array}$ \\
\hline - People & $\begin{array}{l}\text { - Can the results be used to motivate and manage } \\
\text { staff/farmers involved in data collection? }\end{array}$ & \\
\hline
\end{tabular}

Fifthly, the success of monitoring is related to what the objective of monitoring is and how carefully monitoring procedures are thought out. Many factors are involved and each should be addressed with one question; how relevant is it? In other words, managers need to be wary of collecting information for the sake of collecting information, and ensure that steps along the way should quickly lead to other steps; it is just as important to add procedural stages as it is to delete or short-cut others.

Sixthly, apart from flow measurement which needs relatively high capital investment to construct and repair structures, other procedures involve mostly recurrent costs. Whereas this is advantageous, they involve person management which is problematic, and it is necessary to consider factors which affect the motivation of staff such as a sense of responsibility, of being listened and responded to, and salary levels.
Lastly, from the author's experience and from the literature regarding traditional irrigation, farmers manage irrigation using implicit forms of monitoring set against unwritten operational procedures. In an example in Sri Lanka, complex operational rules were adhered to by villagers [6]. On small-scale schemes, farmers readily know how long a field takes to irrigate thereby measuring performance against average performance. This works when fields are small, flows are circulated with few divisions and when farmers over time recognise spatial and temporal relationships between flow rate, time, area, crop, climate, losses, soil conditions and irrigation interval. However, such relationships are difficult to discern on larger schemes and it is on these that more formalised monitoring has the greatest potential impact.

\section{Obtaining quantitative information for monitoring}

\subsection{Introduction}

For irrigation managers, a high priority remains the need to obtain useful quantitative information in order to monitor irrigation management and performance. In this section three main ways are suggested. The first two address flow measurement and the third proposes a method of monitoring without flow measurement.

\subsection{Monitoring using key-location flow measurement}

One approach to flow measurement is to identify the key-location structures providing the most cost-effective information. The most elegant answer to this lies in the hierarchical nature of irrigation systems. Table 2 reveals for a 10,000 ha irrigation scheme, the number of turnouts required at different levels. The 23 structures down to the secondary level could be argued as being the key-location structures. However, it is not clear what can be done with the 8400 structures on the distribution system. Where rotational flows exist, one answer is to reduce the number of measuring turnouts by creating grouped canal networks, used for rotating the leadstream (main d'eau), centred around a single nodal turnout. The disadvantage is that canal networks of existing schemes would need to be altered. In the example in table 2, grouping four 25 ha tertiary networks results in a reduction of 400 to 100 turnouts requiring flow measurement. However, at the lowest level, grouping of farms still leaves high numbers of outlets requiring measurement. For example, grouping of 7 farms results in 1143 measuring outlets. At this level, the solution in section 3.3 is recommended.

Table 2. Numbers of command units, canals and turnouts on a large-scale irrigation scheme

\begin{tabular}{lllll}
\hline Level to level interface & $\begin{array}{l}\text { Usual name of } \\
\text { structure }\end{array}$ & $\begin{array}{l}\text { No. of divisions } \\
\text { per canal }\end{array}$ & $\begin{array}{l}\text { Command } \\
\text { area per outlet }\end{array}$ & $\begin{array}{l}\text { Total number } \\
\text { required }\end{array}$ \\
\hline River to main canal & Intake & 1 & $10,000 \mathrm{ha}$ & 1 \\
Main to main branch & Offtake & 2 & $5000 \mathrm{ha}$ & 2 \\
Main branch to secondary & Offtake & 10 & $500 \mathrm{ha}$ & 20 \\
Secondary to tertiary & Offtake/turnout & 20 & $25 \mathrm{ha}$ & 400 \\
Tertiary to farm outlet & Outlet/turnout & 20 & $1.25 \mathrm{ha}$ & 8000 \\
\hline
\end{tabular}

3.3 Monitoring using passive flow measurement 
Another solution at the tertiary and farm turnout level is to use passive flow measurement (putting aside arguments for automatic means). Passive flow measurement can be designed into the turnout - a common design being the modular gate. The flow is not necessarily observed or recorded but can be "measured" by simply opening shutters. The duration of flow is used to determine the volume discharged. Passive flow measurement is also possible where a flow previously measured upstream is split by a proportional divisor into two or more flows. In all such cases, tertiary head control is necessary to minimise fluctuations in water levels.

\subsection{Monitoring using no flow measurement}

A method is described, using easily recorded data, to monitor irrigation at the tertiary level without flow measurement. It allows irrigation managers to set targets and compare performance against them. The key concept is 'irrigation progress', in hectares/day, calculated for an individual field over time from the following equation:

$$
\text { Irrigation progress }(\text { ha/day })=\frac{\text { command area of field (ha) } \mathrm{x} \text { no. irrigations }}{\text { total duration of irrigation (days) }}
$$

The number of irrigations is over the peak season and the total duration of irrigation is over the same period. The irrigation progress is used to calculate the potential interval period between irrigations which assumes no stops are made due to rain:

$$
\text { Potential interval period (days) }=\frac{\text { leadstream duty area (ha) }}{\text { irrigation progress (ha / days) }}
$$

The leadstream duty area is the nominal duty area served by a single rotating leadstream (see equation 4). The irrigation progress or potential interval of irrigation can be compared to calculated targets of the same, determined from the following:

$$
\text { Gross daily crop water use }(\mathrm{mm} / \text { day })=\frac{\text { Reference crop ETo } \times \mathrm{kc}}{\text { management allowed efficiency \% }}
$$

Nominal leadstream duty area $(\mathrm{ha})=$ secondary unit command area $(\mathrm{ha})$

Target irrig. prg. $($ ha/day $)=$ duty area $($ ha $) \times \frac{\text { gross daily crop water use }(\mathrm{mm} / \text { day })}{\text { soil } \operatorname{RAM}(\mathrm{mm})}$

soil RAM (mm)

Target (no rain) interval (days) $=\overline{\text { gross daily crop water use }(\mathrm{mm} / \text { day) }}$

In equation 3, the gross daily crop water use includes the reference crop evaporation (ETo), the crop factor $(\mathrm{Kc})$ for full canopy water use and the management allowed efficiency (MAE) for irrigation losses at the tertiary level (field and canal). Soil RAM (equation 5) is readily available moisture which includes the management allowed deficit. RAM is therefore the net target refill dose of irrigation in $\mathrm{mm}$.

By comparing these results, indicators of performance may be determined, such as relative efficiency (set against management allowed efficiency) or a computed efficiency (recalculated against a management allowed efficiency of 100\%)

$$
\text { Computed irrigation efficiency } \%=\frac{\text { target interval (days) } \times \text { MAE } \%}{\text { potential target (days) }}
$$

An example clarifies the use of these equations. It is first necessary to calculate the target performance figures. The gross daily water use (equation 3 ) of $7.43 \mathrm{~mm} /$ day is from a ETo of $5.0 \mathrm{~mm} /$ day, a crop factor of 1.0 and an MAE of $70 \%\left(=5.0^{*} 1.0 / 0.7\right)$. The nominal duty area (equation 4) for a secondary unit of 350 ha with 12 leadstreams is 29.2 ha per leadstream $(=350 / 12)$. The target progress rate (equation 5$)$ is found to be $3.33 \mathrm{ha} /$ day from the duty area, gross water use and a soil RAM of $65 \mathrm{~mm}$ (= $29.2 * 7.43 / 65)$. The target interval (found from equation 6 ) is 8.75 days $(=65 / 7.43)$.

The next stage is to determine the actual irrigation progress rates which shows whether any particular field has too-quick or too-slow irrigation. As an example, one 7.8 ha field over a four month period (using sugarcane) receives 8 irrigations, and takes a total of 24 days. The irrigation progress (equation 1) is found to be $2.60 \mathrm{ha} /$ day $(=7.8 * 8 / 24)$. The potential irrigation interval (equation 2$)$ is found to be 11.2 days (= 29.2/2.60). By comparing the potential and target irrigation interval, and assuming both are correct, the computed irrigation efficiency is found to be $55 \%$ (= $8.75^{*} 0.7 / 11.2$ ). In addition the following guidelines and assumptions apply:

1. The method is used during the peak period of water demand where and when managers schedule irrigation with a fixed dose per irrigation but alter the frequency.

2 . It requires a constant secondary flow so that the number of leadstreams operating in equation 4 can be used to determine the nominal duty areas.

3. Actual progress is determined for individual fields as it may not possible to specify the precise duty areas that leadstreams repeatedly rotate around. If leadstreams do stick to set command areas then the method is applied to that group of fields.

4. It requires roughly even ratios between flow to area within the secondary area so that irrigation progress is accountable to losses rather than differing designs and $1 / \mathrm{sec} / \mathrm{ha}$ ratios; in such cases correction factors will be needed.

5. It is possible to determine weighted averages of performance and targets for the whole secondary unit using areas of the individual fields within the secondary unit.

6. Equity indicators (e.g. the coefficient of variation) may be calculated by examining variations in progress between fields, tertiary or secondary units.

7. Note that the irrigation progress is determined from averaging the duration of irrigation with the number of irrigations over the peak season. This smoothes out short term changes in irrigation progress due to early irrigation timing after rainfall.

8. The potential interval is compared to the target interval as given in equation 6 , not to the actual interval which includes stoppages for rain. 
9. The errors in this method arise when calculating meaningful targets from the values of ETo, RAM, efficiency and especially the number of leadstreams operating in the secondary canal which can change over time with differing volumes of water

In summary, irrigation progress is a measure of the ability of the irrigation schemes to maintain the required frequency of irrigation, reflecting the way in which surface irrigation schemes can cope with periods without rainfall. Less efficient schemes will irrigation schemes can cope with periods without rainfall. Less efficient schems
have a lower progress rate, and consequently a higher interval between irrigations.

\section{The management of monitoring}

This section discusses four issues regarding the management of monitoring:

1. Irrigation management: management of monitoring and irrigation management depend on and respond to each other in situations of both pre- and post introduction of monitoring. If monitoring is not present, informal water management rules are required against which operation may be informally gauged. In the second situation, if formalised monitoring is in place but irrigation water is not well managed (and is not improving) then the monitoring of water management (and managed (and is not improving) then the monitoring
performance) becomes a rather meaningless exercise.

2. Use of computers: in monitoring, computers are usually used for two main purposes; to enter, store and retrieve data for areas and to generate summary information for larger areas and for end-of-season reports. A third important use for them is rarely found; to add relevancy to the monitoring information, which is done in four ways. The first is to predict, from actual irrigation progress, the delay in scheduling and its effect on crop water stress and yield; the second is to locate problems and successes; the third is to identify the procedures and people involved in problems and successes, and the fourth is to do these three concurrently with the data collection stage rather than several months later. By setting up the relevant sub-routines within computer programmes and spreadsheets, managers can be directly involved in seeing the output of their irrigation management.

3. Devolving responsibility: in keeping with trends in irrigation management, ways should be found of allowing farmer associations and gatekeepers to monitor their own management while ensuring that it remains the irrigation managers' role to assist farmers in achieving their goals of higher productivity and saving water.

4. Phased programmes: interventions may be planned so that the success of each stage encourages the implementation of the next. Instead of beginning with a monitoring Although linear pathways of implementation are a contradiction in terms in irrigation management, goals can and should be prioritised, such as; identifying responsibilities, data collection, codification; time recording; computerisation; standardisation of record collecting; setting simple targets; and a phased introduction of key-location flow measurement and rehabilitation of turnouts.

5 Conclusions
This paper briefly presents some ideas on the monitoring of surface irrigation schemes. These ideas were first discussed in a general manner (see table 1), followed by three suggestions for obtaining quantitative information on irrigation performance. Finally, some thoughts on the management of monitoring were discussed. The paper reminds irrigation managers of the following:

- It is important to distinguish between flow measurement and information on management and performance. Managers should seek ways of generating and encouraging the latter.

- Time and area measurements on irrigation schemes are of great value. They are, for example, the basis of monitoring of traditional warabundi systems.

- Climate, soil, crop and irrigation design data can be used to determine targets which in turn can be used to evaluate performance.

- Computers can generate relevancy between collected data and performance.

- Managers may accept an argument of no monitoring, but have to be much more proactive towards setting informal standards and operational rules.

- Flow measurement is an achievable 'high goal' and its introduction should be seen within the existing monitoring and irrigation contexts of each scheme. It will be most needed in areas where water is a scarce resource or where its apportionment to users is being accepted via pricing mechanisms or where diagnostic-orientated monitoring is required to raise productivity.

- It is concluded that flow measurement at key points, passive flow measurement where possible, and recording of irrigation progress, are cost-effective options for irrigation managers to consider. The management of monitoring should be clearly thought out from codification through to computerisation, and acknowledge the reinforcing linkages between monitoring and management of water.

\section{References}

1. Walker, W.R. and Skogerboe, G.V. (1987) Surface Irrigation. Theory and Practice, Prentice Hall, New Jersey.

2. Clemmens, A.J., Bos, M.G. and Replogle, J.A. (1993) FLUME: Design and calibration of long-throated measuring flumes. ILRI Publication 54, Wageningen.

3. Abernethy, C.L. and Pearce, G.R. (1987) Research needs in third world irrigation. Proceedings of a colloquium, Hydraulics Research Wallingford.

4. Wolter, H. (1994) Capacity building to implement supervisory control systems in China and India. Theme topic. GRID Issue 4. March 1994. IPTRID Network Magazine, Wallingford.

5. Carruthers, I and Small, L. E. (1991) Farmer-financed irrigation: the economics of reform, Cambridge University Press, Cambridge.

6. Leach. E. (1980) Village irrigation in the dry zone of Sri Lanka, in Irrigation and Agricultural Development in Asia. Perspectives from the Social Sciences, (ed. E.W. Coward, Jr.), Cornell University Press, Ithaca and London. 